\title{
The Enigma of Organic Phosphorus Preserved in Marine Sediments
}

\author{
KATHLEEN C RUTTENBERG ${ }^{1}$ AND REBECCA BRIGGS ${ }^{2}$ \\ ${ }^{1}$ University of Hawaii \\ ${ }^{2}$ U.S. Department of Commerce \\ Presenting Author: kcr@hawaii.edu
}

The origin of the organic phosphorus $\left(\mathrm{P}_{\text {org }}\right)$ found in marine sediments includes the suite of biochemicals that are synthesized by living organisms. We think of these as inherently labile compounds, and as such, the fact that $\mathrm{P}_{\text {org }}$ is preserved, even in very ancient sediments, remains an enigma. Most methods for quantifying the bulk $\mathrm{P}_{\text {org }}$ reservoir in marine sediments use a fairly aggressive acid extraction to solubilize inorganic $\mathrm{P}$ in order to directly quantify $\mathrm{P}_{\text {org }}$ (e.g., as in the SEDEX method of Ruttenberg $(1992,2009))$ or to quantify $\mathrm{P}_{\text {org }}$ by difference (e.g., Aspila et al. (1976)). Application of such methods to freshly deposited organic matter may result in loss of the labile fraction of particulate $\mathrm{P}_{\text {org }}$, and possibly its incorrect attribution to inorganic-P reservoirs. This labile $\mathrm{P}_{\text {org }}$-loss effect will likely be amplified for water column particulate matter, which may be dominated by living organisms (e.g., plankton).

To address the potential problem of incomplete recovery of $\mathrm{P}_{\text {org }}$ from marine sediments due to under-recovery of labile $\mathrm{P}_{\text {org }}$, we have explored addition of a pre-extraction step to the SEDEX method designed to separately quantify labile $\mathrm{P}_{\text {org }}$ prior to subjecting sediments to the more aggressive subsequent SEDEX extraction steps. After discussing results of standardization experiments conducted to evaluate the efficacy and specificity of labile $\mathrm{P}_{\text {org }}$ pre-extraction from sediments, we will present some unanticipated results that raise intriguing questions about the nature of the $\mathrm{P}_{\text {org }}$ pool that is preserved in marine sediments.

Aspila, K.I., Agemain, H. and Chau, A.S.Y. (1976) A semiautomatic method for the determination of inorganic, organic and total phosphorus in sediments. Analyst 101: 187-197.

Ruttenberg, K.C. (1992) Development of a sequential extraction method for different forms of phosphorus in marine sediments. Limnol. Oceanogr. 37(7): 1460-1482.

Ruttenberg, K.C., Ogawa, N.O., Tamburini, F., Colasacco, N.D., Briggs, R.A. and Monaghan, E.J. (2009) Improved, high through-put approach for phosphorus speciation in natural sediments via the SEDEX sequential extraction method. Limnol. Oceanogr. Methods 7: 319-333. 